\title{
Stage Fault Test of a Low Voltage Microgrid for Development of Protection Scheme
}

\author{
Shi-Lin Chen ${ }^{\mathrm{a} *}$,Yen-Lin Chen ${ }^{\mathrm{a}}$, Yung-Ruei Chang ${ }^{\mathrm{b}}$, Chen-Min Chan ${ }^{\mathrm{b}}$ \\ ${ }^{a}$ Electrical Engineering Department, Chung Yuan Christian University, Jhongli 32023, Taiwan \\ ${ }^{b}$ Institute of Nuclear Energy Research, Longtan 32546, Taiwan
}

\begin{abstract}
One of the key elements of microgrid is protection system. To design the protection system for a $380 \mathrm{~V}$ microgrid, a stage fault test has been conducted in a microgrid test bed built at the Institute of Nuclear Energy Research (INER), Taiwan. The special feature of ground fault voltage of the $380 \mathrm{~V}$ microgrid is investigated in the test, based on which a protection scheme is proposed. This paper presents the INER microgrid test bed and the stage fault test conducted as well as the preliminary evaluation results of the proposed protection scheme.
\end{abstract}

Keywords: Microgrid, protection, stage fault test

\section{Introduction}

For a higher penetration of renewable energy source (RES) and for a differential power-quality supply, various types of microgrid have been developed [1]-[4]. One of the key issues in development of microgrid is the design of protection system [5]-[8]. Nikkhajoei and Lasseter adopted the zero-sequence current $\left(3 I_{0}\right)$ and the sum of three-phase and neutral current $\left(I_{d}\right)$ irrespectively for the detection of upstream and downstream ground faults [5]. The protection scheme has been successfully tested in the CERTS (Consortium for Electric Reliability Technology Solutions) microgrid [9]. However, there exists a difference on the system grounding configuration between the CERTS $480 \mathrm{~V}$ microgrid and the $380 \mathrm{~V}$ system which has been widely adopted in Taiwan. A $400 \mathrm{~kW}$ sized microgrid test bed (referring to a total capacity of RES at above $400 \mathrm{~kW}$ ) built in Taiwan at the $380 \mathrm{~V}$, to be termed INER (Institute of Nuclear Energy Research) microgrid in this paper, shall be presented in Section 2. Because of the difference on grounding configuration of Taiwan's $380 \mathrm{~V}$ microgrid from that of CERTS, the protection scheme which captures the ground fault current/voltage feature of $380 \mathrm{~V}$ system for INER microgrid has to be designed. Thus, a stage fault test has been conducted and a protection scheme proposed for INER microgrid.

Section 2 shall present INER microgrid and the part of protection system in the design. The difference between Taiwan's 380V grounding system from that of CERTS is also presented in this Section. Section 3 shall present the stage fault test conducted in INER microgrid, including the test procedure and results. The protection scheme proposed on basis of the test results and the preliminary evaluation results on the protection scheme shall be presented in Section 4.

\section{INER Microgrid Test Bed}

A 380V microgrid test bed (termed as INER microgrid) was built at INER of Taiwan in year 2010. Referring to Fig. 1 and Fig. 2, the microgrid is comprised of a static switch, a $65 \mathrm{~kW}$ microturbine, a 150 kW HCPV (high concentration photovoltaics) and a total $175 \mathrm{~kW}$ wind turbine. In addition to these

\footnotetext{
* Manuscript received June 15, 2012; revised July 25, 2012.

Corresponding author. Tel.: +886-3-265-4828; fax: +886-3-265-4899; E-mail address:slchen@dec.ee.cycu.edu.tw.
} 
distributed sources (DS's), the microgrid is also comprised of a control room and a DC powered house. According to the simulation of INER [10], the single-phase-to-ground fault at location $\mathrm{F}_{1}$, depicted in Fig. 2, is $5.76 \mathrm{kA}$, which is mainly provided by the utility grid. Under the islanded operation, the fault current at F1 and other fault locations in the microgrid are all less than $0.2 \mathrm{kA}$, as it has been assumed in the simulation[10] that the fault current provided by the converters of DS's are less than 2 times of the rated current [9]. Therefore, the protection system of the INER microgrid has been designed as follows:

- Grid connected operation: Fault is detected and isolated by no fuse breaker (NFB). As during the grid connected operation, digital relays have been locked out according to the status (open/close) of static switch.

- Islanded operation: Fault is detected by digital relay and isolated by magnetic contact, which is the part to be investigated in this paper.

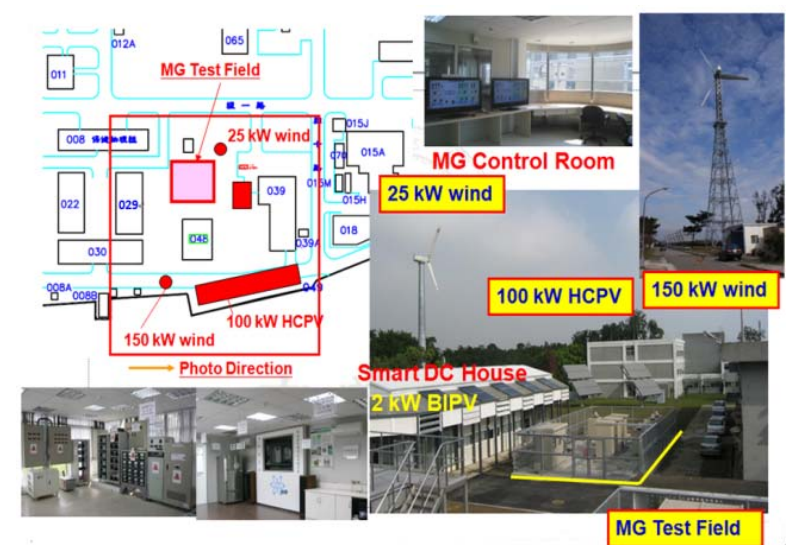

Fig. 1. $400 \mathrm{~kW}$ Sized Microgrid Test Bed at INER

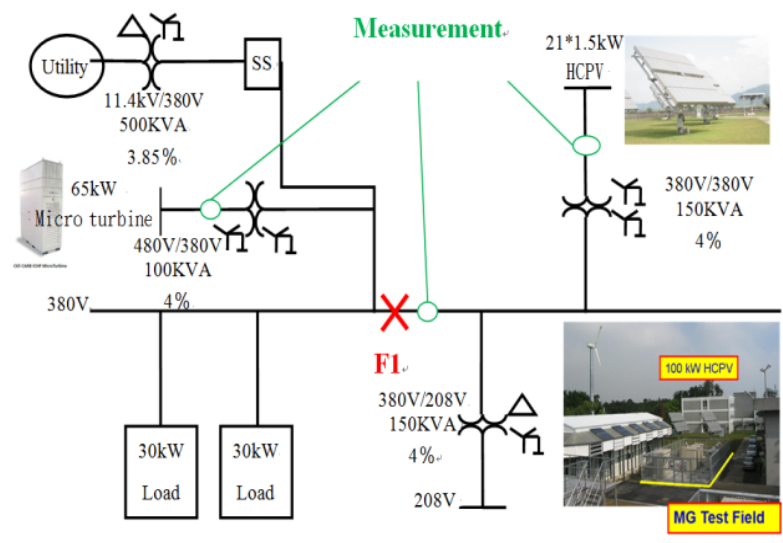

Fig. 2. Fault Location and Measurement Points

Fig. 3 depicts the system grounding configuration of $380 \mathrm{~V}$ INER microgrid. As shown, the $380 \mathrm{~V}$ system is multiply grounded, i.e., in addition to the source transformer, the DG transformers (referring to, that of DG1 and DG2 in Fig. 3) are all grounded, which thus differs from the grounding of $480 \mathrm{~V}$ system of CERTS. In CERTS microgrid, the system is grounded at the source transformer only and the DG transformers are not grounded. The protection scheme which captures the ground fault feature of $380 \mathrm{~V}$ system of INER microgrid thus has to be redesigned.

To understand the characteristic of fault current provided by the DS converter and the voltage of faulted system, a stage fault test was conducted on December 31, 2011. The stage fault test procedure and results are presented in next section.

Note: In $480 \mathrm{~V}$ CERTS microgrid [9], Relay 1 detects the fault by $I_{d}=\left|I_{a}\right|+\left|I_{b}\right|+\left|I_{c}\right|+\left|I_{n}\right|$ which is however not applicable to the $380 \mathrm{~V}$ system, due to the fault current distribution which may not all go through the neutral ground wire of source transformer in the $380 \mathrm{~V}$ system.

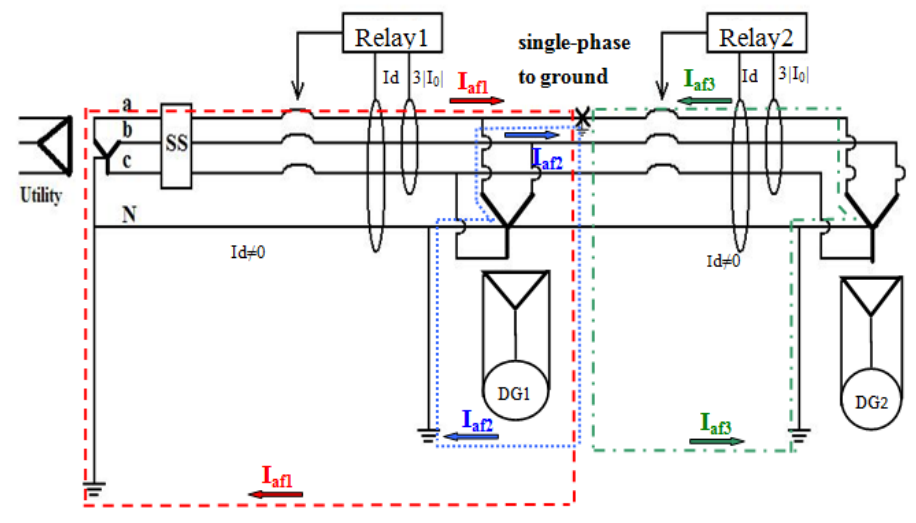

Fig. 3. System grounding configuration of $380 \mathrm{~V}$ microgrid 


\section{Stage Fault Test}

\subsection{Stage fault test}

Before the stage fault test, there was a worry on the safety of Buildings 029 and 030 which contain an experimental process for producing alcohol, as depicted in Fig. 1. The main transformers of Buildings 029 and 030 are located at the right-hand side of the Buildings which is at a distance of 5 meter from the nearest DS transformer in the microgrid. Referring to Fig. 4, the single-phase-to-ground fault at $\mathrm{G}_{2}$ could cause a ground potential rise (GPR) of $\mathrm{G}_{4}$ which refers to the neutral-to-ground of main transformers of Buildings 029 and 030 . Therefore a variable resister at $10 \mathrm{~kW}$ and at the maximum value of 4.8 ohms, had been inserted between the 500 AT NFB (which was then switched to the ground bus to simulate the ground fault) and the fault point, at the beginning of the test to reduce the fault current (The measured was $48 \mathrm{~A}$ ). In the meantime, we observed the GPR of $\mathrm{G}_{4}$ relative to a remote ground electrode which was installed 30 meters away from $\mathrm{G}_{4}$. Because the GPR observed was almost zero, the resister was then removed and a direct ground fault was applied (with a measured fault current of 511 A at fault location F1 in Fig. 2). If the GPR observed were not zero, it had been planned that not more than $65 \mathrm{~V}$ (according to EN50122 [11]) were allowed, based on which to set the applied variable resistor value. During the test, because of the rainy weather, both PV and wind turbine were not operated. To prevent fault current from damaging the microturbine, a high speed fuse (at 40 A $690 \mathrm{~V}$ ) was additionally installed before the test to protect the microturbine.

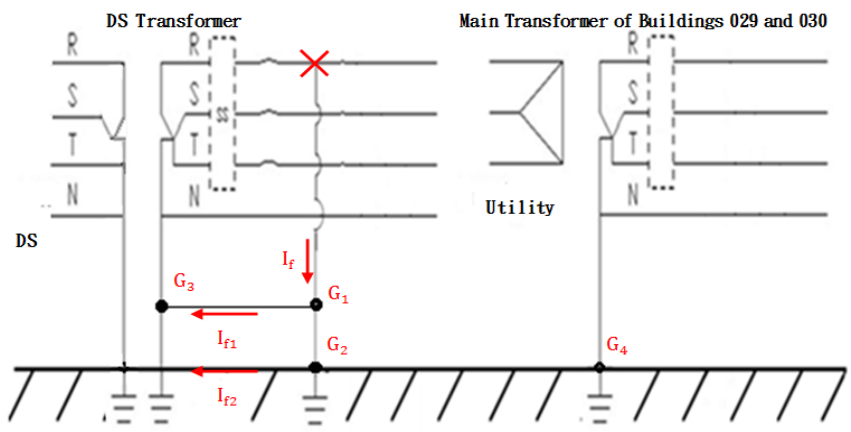

Fig. 4. Fault Current Distribution $I_{f 2}$ Could Cause GPR of $G_{4}$

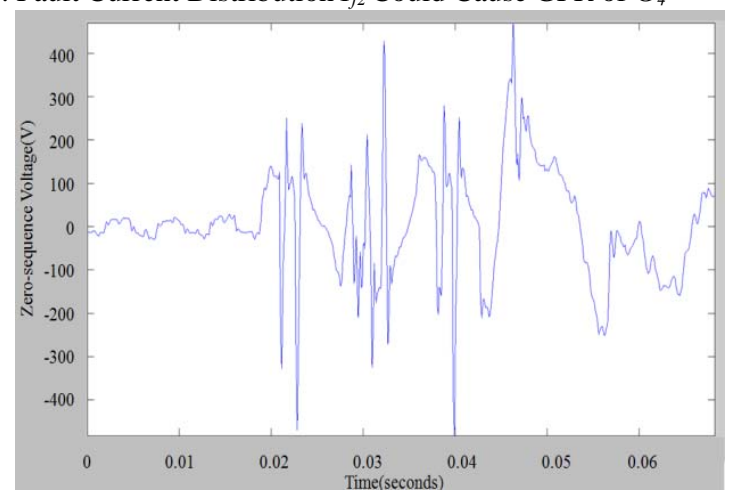

(a)

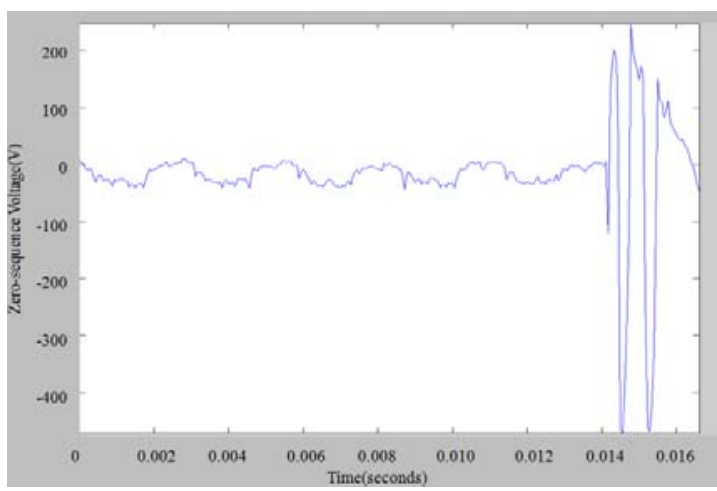

(b)

Fig. 5. Pre-and post-fault zero-sequence voltage $\left(3 \mathrm{~V}_{0}\right)$ waveforms: (a) at microturbine; (b) at fault location $F_{1}$. note: the time axes are different in (a) and (b) because two different recorders were used.

\subsection{Test results}

Referring to Fig. 5, the pre- and post-fault zero-sequence voltage waveforms both at the fault location $\mathrm{F} 1$ and at the microturbine show that the zero-sequence voltage can be adopted to detect the fault. The low-and even-order harmonics, which is relatively higher at the fault location $F_{1}$ than at the microturbine, could be further applied to the detection of faulted zone. However, in our proposed protection scheme, the harmonics are not yet applied, but the square of $3 V_{0}$, denoted as $\left|3 V_{0}\right|^{2}$, was adopted in the present study. 
The load current and voltage measured at Buildings 048 and 049 are now under investigation. By assuming $\left|3 V_{0}\right|^{2}$ distributed in $\lambda^{2}$ [12], the relay pickup at $\left|3 V_{0}\right|^{2}{ }_{95 \%}$ is proposed to detect the fault, with the faulted zone identified by the directional overcurrent scheme, which shall be presented in next Section.

\section{Proposed Microgrid Modulization and Protection Scheme}

\subsection{Zone types designed for modulized microgrid}

Referring to Fig. 6, a microgrid can be modulized into the following three types of zones [13], the load and DS are then distributed among these zones:

(1) Parallel zone: Connected to the main bus, e.g., Zones \#1, \#2 and \#3;

(2) Series zone: Connected to a parallel or a series zone, e.g., Zone \#3-1, \#3-2, \#3-1-1.

Among the series zones, energy storage or dispatchable sources as well as the essential load are suggested being located at the upstream series zone such as Zone \#3-1 depicted in Fig. 6.

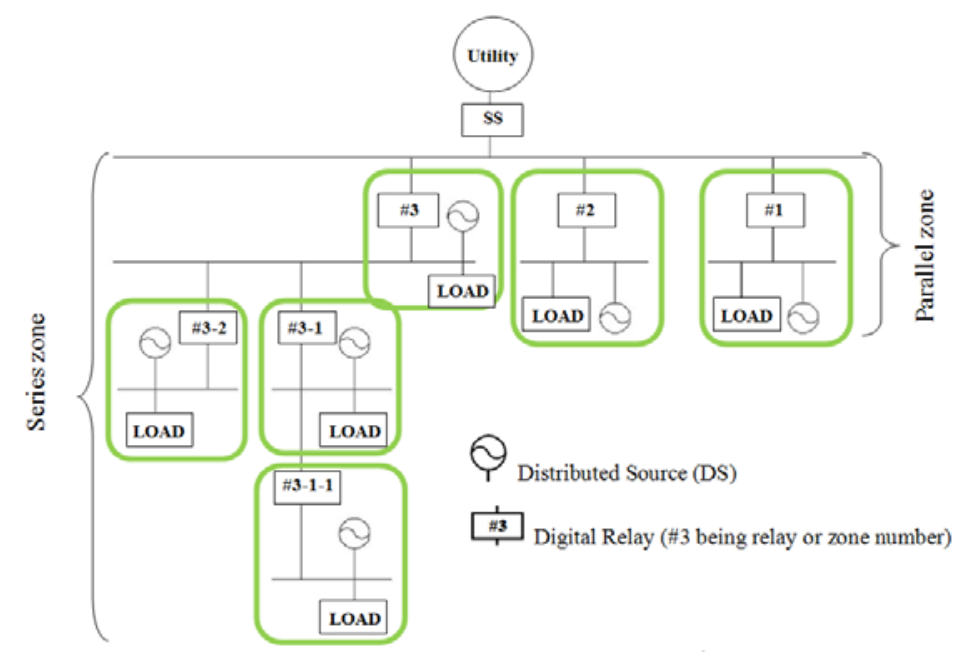

Fig. 6. Zone types designed for modulized microgrid scheme

\subsection{Proposed Protection Scheme}

\section{A. Protection scheme}

For easier presentation of the proposed protection scheme, the INER Microgrid is configured into Fig. 7, by following the notation of Fig. 6. Four Fault locations A D are depicted in Fig. 7. A protection scheme, as depicted in Fig. 8, is proposed to the protection of any modularized microgrid of Fig. 6. The protection scheme is comprised of two parts by referring to Fig. 8 where the notation in the diagram follows [14]: 1) Fault detection: by $\left|3 V_{0}\right|^{2}$ and $\mid I_{\text {phase }}$, and 2) Fault direction identified: by the commonly used directional overcurrent scheme.

The relay settings are based on the following principles.

1) For the parallel and downstream series zone (e.g., Zone 1 and Zone 3 in Fig. 7)

To detect the local fault, i.e., the fault located inside the zone, the relay is set at the direction forwards the local fault and the settings are $\left|3 V_{0}\right|^{2}>\left|3 V_{0}\right|^{2}{ }_{95 \%}, I_{\text {phase }}>1.5 I_{\text {load, rated, }}$, where $I_{\text {phase }}$ is the phase current denoted as $I_{1}$ in Fig. 8, $I_{\text {load,rated }}$ refers to the rated of local load, and $\left|3 V_{0}\right|^{2}{ }_{95 \%}$ is the $95 \%$ confidence level of $\left|3 V_{0}\right|^{2}$ distribution under the normal load condition [12]. $\left|3 V_{0}\right|^{2}{ }_{95 \%}$ can be refined automatically according to the on-line measurement of load [12].

To detect the remote fault, referring to the fault located out of the zone where the digital relay is resided, the direction of relay is towards the remote fault and the relay settings are $\left|3 V_{0}\right|^{2}>\left|3 V_{0}\right|^{2}{ }_{95 \%}$, $I_{\text {phase }}$

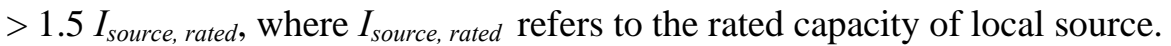

2) For the upstream series zone (e.g., Zone 2 in Fig. 7)

The relay direction and $3 V_{0}$ setting are the same as in 1), but the overcurrent settings are $I_{\text {phase }}>1.5$ $I_{\text {source, rated }}^{*}$ for detecting the local fault, and $I_{\text {phase }}>1.5 I_{\text {load, rated }}^{*}$ for detecting remote fault, where $I_{\text {source, }}^{*}$ 
rated and $I_{\text {load, rated }}^{*}$ refer to the sum of rated capacity for the DS's and the sum of rated load, both out of the zone where the digital relay is resided.

Take the relay setting of INER microgrid as an example, the relay settings can thus be compiled into Table1, according to the source and load data in Fig. 7.

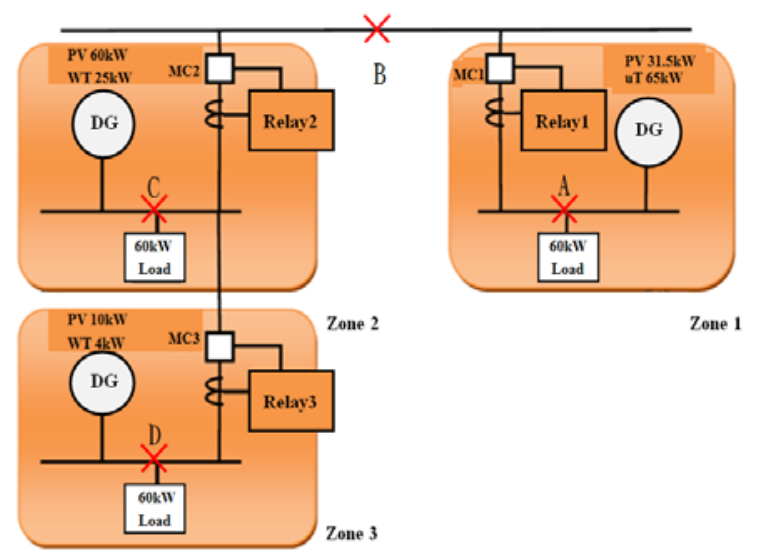

Fig. 7. The configuration and fault location of inner microgrid for presentation of proposed protection scheme

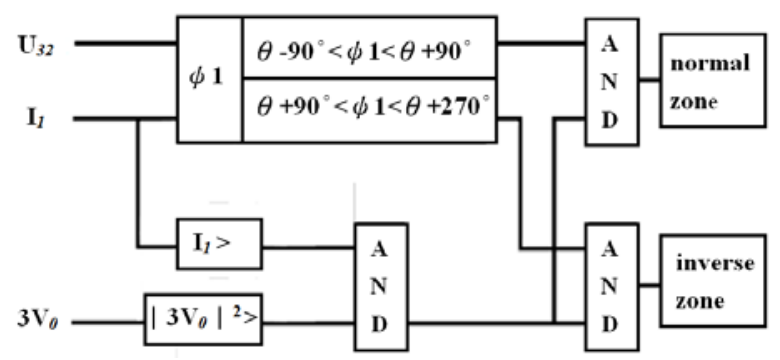

Fig. 8. Operating Mechanism of Proposed Protection Scheme.

Table 1. Relay Settings Proposed for Islanded Operation of INER Microgrid

\begin{tabular}{|c|c|c|}
\hline \multirow{2}{*}{ Relay No. in Fig. 7 } & \multicolumn{2}{|c|}{ Fault Location } \\
\cline { 2 - 3 } & Inside the Zone & Outside the Zone \\
\hline \multirow{2}{*}{$\#$ Relay } & $I_{\text {phase }}: 136.5 \mathrm{~A}$ & $\mathrm{I}_{\text {phase }}: 219 \mathrm{~A}$ \\
\cline { 2 - 3 } & TT: $0.2 \mathrm{~s}$ & TT: $0.6 \mathrm{~s}$ \\
\hline \multirow{2}{*}{ \#2 Relay } & $I_{\text {phase }}: 219 \mathrm{~A}$ & $I_{\text {phase }}: 136.5 \mathrm{~A}$ \\
\cline { 2 - 3 } & TT: $0.4 \mathrm{~s}$ & TT: $0.4 \mathrm{~s}$ \\
\hline \multirow{2}{*}{$\# 3$ Relay } & $I_{\text {phase }}: 136.5 \mathrm{~A}$ & $I_{\text {phase }}: 31.5$ \\
\cline { 2 - 3 } & TT: $0.2 \mathrm{~s}$ & TT: $0.6 \mathrm{~s}$ \\
\hline
\end{tabular}

\section{B. Numerical verification}

By assuming the fault current provided by each DS converter is 2 times of the rated, the local fault currents are Zone 1: 292A, Zone 2: 258A, and Zone 3: $42 \mathrm{~A}$ [13].

1) Fault at location A (Fig. 7)

Because the fault current $(300 \mathrm{~A}=258 \mathrm{~A}+42 \mathrm{~A})$ is higher than 1.5 times the rated of local load current, Relay\#1 will trip in $0.2 \mathrm{~s}$ (ref. Table 1) to isolate zone 1 from the main bus, and the DS converter within Zone 1 will also trip to isolate the DS from fault. In the meantime, Relay\#2 detects the fault, but the tripping time of Relay\#2 is set at 0.4 s (ref. Table1), which can thus act as the backup.

2) Fault at location B (Fig. 7)

Relays\#1 and \#2 detect the fault and trip in $0.6 \mathrm{~s}$ and $0.4 \mathrm{~s}$ respectively to isolate the fault at main bus from Zones 1 and 2. Relay \#3 can also trip in 0.6s, which can thus act as the backup of Relay\#2.

3) Fault at location C (Fig. 7)

Relays \#2 and \#3 can detect the fault and trip in 0.4s and 0.6s respectively to isolate the fault from Zones 1 and 3. Relay\#1 can also trip in 0.6s, thus acting as the backup of Relay\#2.

4) Fault at location D (Fig. 7) 
Because the current $(550 \mathrm{~A}=292 \mathrm{~A}+258 \mathrm{~A})$ exceeds the relay setting (136.5A), Relay\#3 trips in $0.2 \mathrm{~s}$ to isolate fault from Zone 2. Relays \#2 and \#1 can also trip in $0.4 \mathrm{~s}$ and $0.6 \mathrm{~s}$, which can thus act as the backup of Relay\#3.

\section{Conclusions}

The INER microgrid test bed and the stage fault test conducted as well the preliminary evaluation results of proposed protection scheme were presented in this paper. Several concluding remarks enlisted below can be drawn from the study:

1) The grounding configuration of $380 \mathrm{~V}$ microgrid differs from that of $480 \mathrm{~V}$ microgrid. The $I_{d}$ adopted for the detection of ground fault of $480 \mathrm{~V}$ microgrid is thus not applicable to the $380 \mathrm{~V}$ microgrid (ref. Fig. 3).

2) The stage fault test procedure presented is Subsection 3.1, which makes use of EN50122 to set the maximum fault current or the minimum variable-resistor value, can be applied to the test of microgrid having the safety consideration for persons and equipments in the proximity of the microgrid.

3 ) The magnitude of zero-sequence voltage $\left(\left|3 V_{0}\right|\right)$ can be used as a ground-fault detection variable in the design of protection system for the $380 \mathrm{~V}$ microgrid. The faulted zone can be detected by the directional overcurrent scheme.

The load current and voltage measurements are now under investigation for the distribution of $\left|3 V_{0}\right|^{2}$ and its 95\% confidence level, if $\lambda^{2}$ distribution is observed. A digital relay is also studied to implement the relaying scheme for the future sensitivity and dependability tests of the scheme.

\section{Acknowledgements}

The authors wish to thank National Science Council for the financial support of this study (project number 100WBS0300012)

\section{References}

[1] Hatziargyriou N, Asano H, Iravani R, Marnay C. Microgrids. IEEE Power and Energy Magazine, 2007; 5(4):78-94.

[2] Kroposki B, Lasseter R, Ise T, Morozumi S, Papatlianassiou S, Hatziargyriou N. Making microgrids work. IEEE Power and Energy Magazine, 2008; 6(3):pp.40-53.

[3] Katiraei F, Iravani R, Hatziargyriou N, Dimeas A. Microgrids management. IEEE Power and Energy Magazine, 2008; 6(3):pp.54-65.

[4] Driesen J, Katiraei F. Design for distributed energy resources. IEEE Power and Energy Magazine, 2008; 6(3):30-40.

[5] Nikkhajoei H, Lasseter RH. Microgrid protection. Presented at: 2007 IEEE Power and Energy Society (PES) General Meeting .

[6] Laaksonen H, Kauhaniemi K. Fault type and location detection in islanded microgrid with different control methods based converters. Presented at: the 19th Int. Conf. on Electricity Distribution (CIRED).

[7] Al-Nasseri H, Redfern MA. A new voltage based relay scheme to protect micro-grids dominated by embedded generation using solid state converters. Presented at: the 19th Int. Conf. on Electricity Distribution (CIRED)

[8] Al-Nasseri H, Redfern MA. Harmonics content based protection scheme for micro-grids dominated by solid state converters. In: Proc. of the 12th Middle East Power Syst. Conf, 2008:50-56.

[9] CERTS microgrid test bed. [Online]. Available: http://certs.aeptechlab.com/.

[10] Lo WT, Chen SL, Hsu SH, Chang YR. Protection coordination of microgrid. Presented at: the 31th Symposium on Electrical Power Engineering.

[11] EN 50122. European Committee for Electrotechnical Standardisation.

[12] Lien KY, Chen SL, Liao CJ, Guo TY, Lin TM, Shen JS. Energy variance criterion and threshold tuning scheme for high impedance fault detection. IEEE Trans. on Power Delivery, 1999; 14(3):810-817.

[13] Lee YJ, Chen SL, Chang YR. Planning and design of protection system for a low-voltage microgrid. Presented at: the 31th Symposium on Electrical Power Engineering.

[14] Sepam 2000 Metering and Protection Functions, Research report. Schneider Electric, 2000. 